\title{
1 A resistance type vertical axis wind turbine for building 2 integration
}

3

4 Authors:

5

6

7

8

9

10

11

12

13

\section{Abstract:} mill

Gerald Müller, Associate Professor, Faculty of Engineering and the Environment, University of Southampton, Highfield, Southampton SO17 1BJ, UK.

Tel.: +44 2380 592465. Email: g.muller@soton.ac.uk

Mert Chavushoglu, Undergraduate Student, Faculty of Engineering and the Environment, University of Southampton, Highfield, Southampton SO17 1BJ, UK

Mark Kerri, Undergraduate Student, Faculty of Engineering and the Environment, University of Southampton, Highfield, Southampton SO17 1BJ, UK

Toru Tsuzaki, Research Officer, Faculty of Engineering and the Environment, University of Southampton, Highfield, Southampton SO17 1BJ, UK

The Persian or Sistan wind mill is possibly the oldest wind energy device. It consists of a vertical axis with six blades, and an outer shroud which encases half the rotor against the wind. The wind only acts on one half of the runner, providing the driving force. The efficiency of this machine was assumed to be between 5 and 14\%, too low for practical application today. The concept however is interesting since it has the potential for integration into buildings. Recently, the Sistan wind mill was re-visited to assess whether the performance could be improved. Initial exploratory tests reported in the literature indicated potential. At Southampton University, a series of tests was conducted with a model of $0.6 \mathrm{~m}$ diameter and $0.5 \mathrm{~m}$ high runner employing an improved measurement and data acquisition system. Two geometries were investigated. Qualitative tests indicated that a gap between blade and axis is essential for functionality. Performance tests with an improved geometry resulted in efficiencies of 0.4 to 0.5 , similar to e.g. Darrieus-type VAWTs, for blade to wind speed ratios of 0.82 to 1.8 . The modified resistance-type vertical-axis wind turbine appears to have potential for further development.

Key words: vertical axis wind turbine, building integration, resistance type wind turbine, Sistan wind

\section{Introduction}

The integration of wind turbines into buildings constitutes an interesting aspect of wind energy application. The direct proximity of generation and end user would create very favourable conditions for wind energy usage. A brief overview over current concepts of wind energy integration into building is given in [1]. Vertical Axis Wind Turbines (VAWTs) are hereby considered as better suited for this purpose. The most common VAWT today is the Darrieus-turbine, which employs the forward 
acting forces generated on an airfoil. Such turbines have an efficiency of up to 0.40 [2]. They do not need active components since they rotate in the same direction irrespective of the direction of the wind although speed control is necessary. There are however several factors which negatively affect the integration of wind turbines into buildings and built-up areas:

1. Architecture: propeller turbines and vertical axis wind turbines (VAWTs), which employ the Darrieus principle, are difficult to integrate into buildings.

2. Turbulence: both propeller and Darrieus type turbines are affected by the turbulent air flow created by buildings and surface obstacles.

3. Environment: the fast moving tips of propeller blades are considered as dangerous for many flying animals such as birds and bats. In addition, the blades create moving shadows and low frequency noise, which may affect people working or living near these installations.

Today, there is no turbine type which is easy to integrate into buildings. The principle of the oldest wind energy converter, the Persian or Sistan wind mill, may however offer a solution.

\section{Literature review}

The Persian or Sistan wind mill is the oldest type of wind mill, it origins go back to the $9^{\text {th }}$ Century, e.g [3]. This wind mill constitutes resistance type wind energy converter. It consists of a vertical axis runner, often 3-4 m high, with six to eight blades of 2 to $3 \mathrm{~m}$ width, Fig. 1a. One side of the runner, the side moving against the direction of the wind, is encased in a semi-circular wall. On the other side, a guide wall focuses the wind onto the blade, Fig. $1 \mathrm{~b}$. This arrangement was effective, since in Khorasan the wind blows in one direction only for 120 days per year. The Persian wind mill was until recently considered as of historical interest only. The efficiency is given in the literature as $\eta=0.14$, and sometimes as low as 0.05 , e.g. [4]. These values were determined using the blade area only for the calculation of the available wind energy. In order to make them comparable with other wind turbines, these factors need to be reduced by at least $50 \%$ to take account of the total area of the mill exposed to the wind.

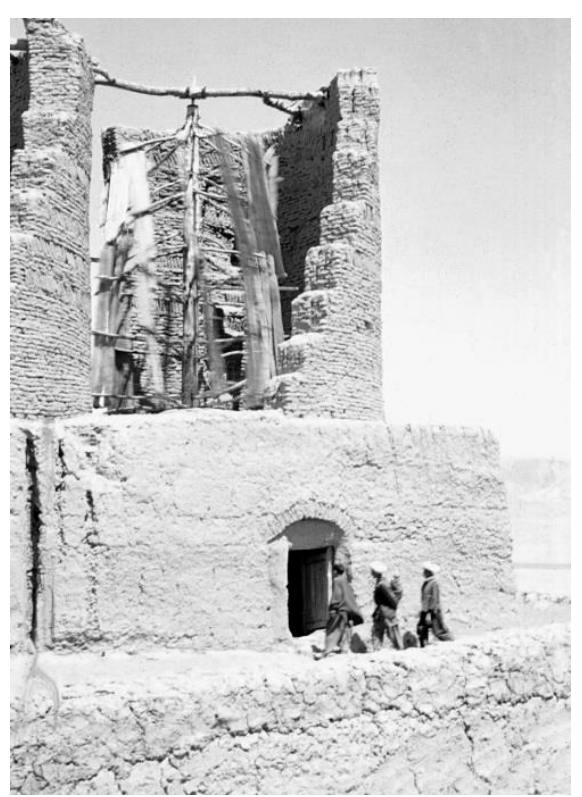

a. Mill near Heart, Afghanistan [5]
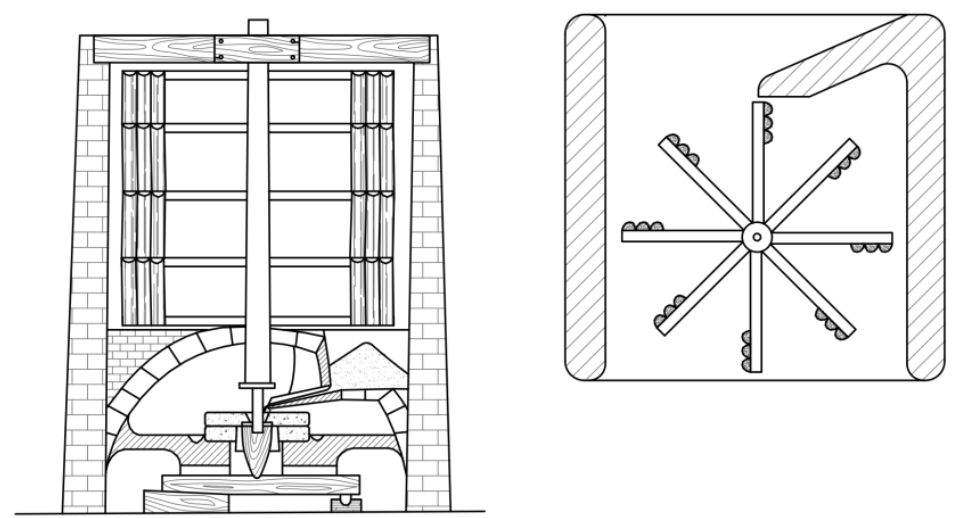

b. Front elevation and plan view [6] 


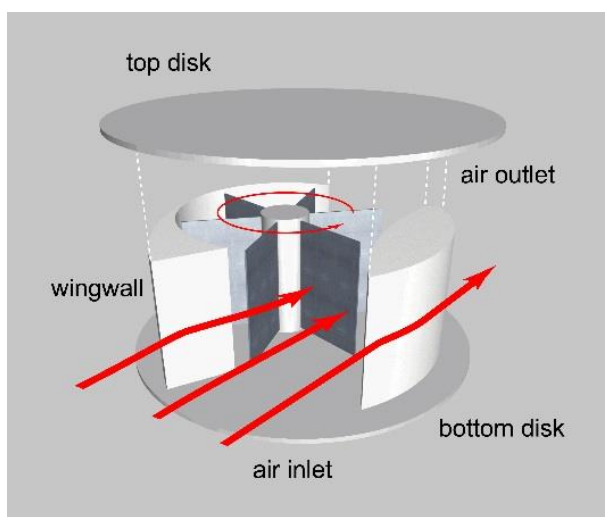

c. Proposed new configuration with movable outer shroud [5]

Fig. 1: Sistan wind mills and proposed new configuration

The Sistan turbine constitutes a visually solid block, contrary to most other wind turbines. This makes the architectural integration of this turbine type into buildings much easier. As a resistance or drag type machine, it can be expected that the Sistan turbine is less affected by turbulence than other VAWTs such as the Darrieus turbine. This is also considered a potential advantage although it has not yet been demonstrated experimentally. Today, the adjustment of the VAWT to the wind direction is possible e.g. by providing a movable outer section or shroud. Compared with propeller type Horizontal Axis Wind Turbines (HAWT), this has the advantage that the rotating part of the turbine does not have to be moved. Fig. 1c shows such an arrangement. In addition, the comparatively slow speed of the rotor combined with its high visibility will very probably mean reduced noise emission and a better ecological performance. Propeller type wind turbines are coming increasingly under criticism for damages to birds, and other flying species of animals [7].

Müller et al. were the first to actually test a model of the Sistan-type turbine [5]. Their motivation was to assess its energy generation and also the potential for building integration. The model tests resulted in efficiencies of $15 \%$ for maximum power for a blade to wind speed ratio of 0.3 , using the total front area of the model as basis for the determination of the input energy (the efficiency was 0.42 when calculated using the blade area only). This was substantially more than the values given in the literature, and was considered a promising starting point. The tests were however preliminary, since the measurement equipment was not adapted to deal with strong variations in wind speed. Following this paper, several modifications of the theme were investigated by researchers:

A problem of the Sistan type VAWTs for present-day application is, that they need to be adjustable to the wind direction. One possibility to do this, is to rotate the outer shroud [5]. In [8], a static outer flow guidance structure, termed external power-augmentation-guide vane (PAGV) for a Sistantype rotor is described, which aligns the direction of the air flow with the turbine blades irrespective of the wind direction. The freely rotating three blade rotor reached a blade to wind speed ratio of $v_{B}$ $/ v_{w}=0.44$. A combined experimental and numerical analysis was performed in order to estimate the power production. This resulted in a maximum efficiency of $18.3 \%$ [9].

A modification of the principle, with a $1.64 \mathrm{~m}$ outer diameter rotor with eight blades of $0.24 \mathrm{~m}$ breadth, and a shroud to cover the returning side of the rotor was tested recently. Efficiencies were $17 \%$ at a blade to wind speed ratio of $v_{B} / v_{w}$ of 0.37 [10].

Burlando et al. investigated a three blade, Savonius type rotor with fixed external guide vanes and a PAGV [11]. These were arranged so as to guide the wind into the curved blade sections irrespective of the wind direction. The blades extended from the axis up to the inner perimeter of the PAGV. 
They conducted wind tunnel tests, and numerical simulations. This work was subsequently extended, looking at more detail into the effect of the stator [12]. Further numerical studies were conducted with a 9-blade, Sistan-type turbine with external guide structure and a closed top [13]. The rotor had a diameter of $6.5 \mathrm{~m}$, with the $1 \mathrm{~m}$ wide blades fixed at the end of the radius. The inlet section was $11.50 \mathrm{~m}$ wide, and funnels the wind into the $3 \mathrm{~m}$ wide inflow opening. The authors investigated the flow inside the turbine housing in detail, but it is unclear whether any negative pressures resulting from flow separation at the downstream end were considered. Also, the counter-rotating side of the downstream end of the turbine appears not to have been covered. The numerical model predicted a blade speed to wind speed ratio of $v_{B} / v_{W}=5.4$. The authors also comment on the formation of vortices inside the turbine, their dynamics and potential negative effects.

From the available literature it can be concluded that resistance type VAWTs have the potential to be effective wind energy converters which can more easily be integrated into buildings than e.g. Darrieus type VAWTs.

\section{Experimental set-up}

\subsection{Model}

At Southampton University, a series of model tests on a Sistan-type, resistance VAWT was conducted. The aim of the project was to determine conversion efficiencies experimentally, and to improve the geometry.

The experiments were conducted with a model VAWT as shown in Fig. 2. The runner has a diameter of $750 \mathrm{~mm}$, and a height of $575 \mathrm{~mm}$. The outer hull is built from $8 \mathrm{~mm}$ square steel sections, with 2 $\mathrm{mm}$ plywood cover inserted on the inside of the steel frame. The outer width of the frame is $800 \times$ $800 \mathrm{~mm}$, with a height of $600 \mathrm{~mm}$. A 45 degree deflector is mounted on the upstream side of the model in order to guide the wind into the opening. Inside the box, a semi-circular shroud covers the right hand side of the runner (Fig. 2 plan view, bottom right).

PLAN VIEW:

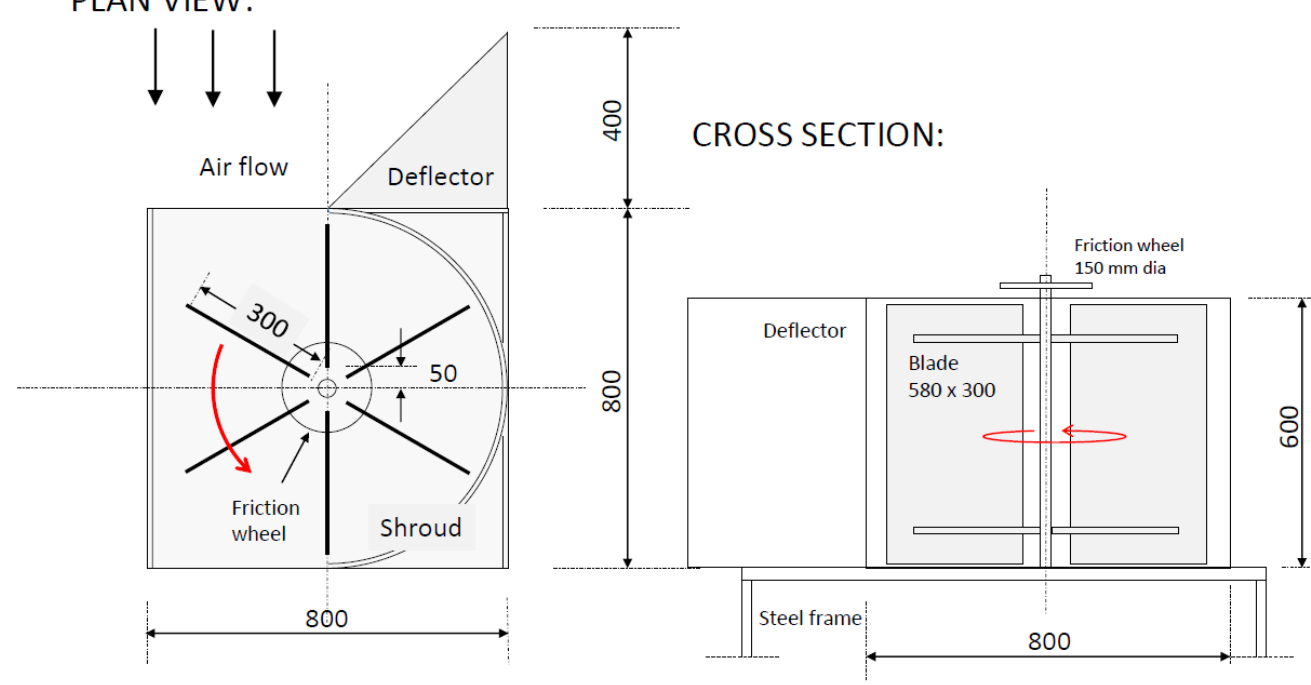

Fig. 2: Model, plan view and cross section

The bottom (downstream) half of the shroud can be removed, so that both constellations - with and without downstream shroud - can be tested. This prevents turbulence at the inflow, and reduces 
the counteracting effect of negative pressures at the outflow. Test were conducted outside, in a narrow road between two buildings, and in a large wind tunnel facility.

\subsection{Data acquisition}

A dedicated LabView based stand-alone measurement system was developed to allow for simultaneous acquisition of wind speed, runner speed and friction force data. The wind speed was monitored using a UNI-T UT361 anemometer placed at roughly $0.5 \mathrm{~m}$ in front of the model at $1 \mathrm{~m}$ height from ground level. The friction force $F_{\mathrm{fr}}$ on the Prony brake was measured with a TEDEA Model 0355 load cell. The rotational speed $n$ of the friction wheel was recorded using a compact digital optical tachometer A2103/LSR/001 from Compact Instruments pointed at the friction wheel. It has speed range of 3 to $99,999 \mathrm{rpm}$. The data from all three sensors was collected digitally with a laptop using LabVIEW (LV2014) based measurement and data analysis software. The anemometer was checked against the wind tunnel Pitot tubes, the tachometer against a stopwatch and the force transducer was calibrated at the beginning of each test series and checked against drift at the end. All three devices were found to be accurate within the manufacturer's information.

The torque $M_{\mathrm{T}}$ generated by the model could be determined by multiplying the friction force $F_{\mathrm{fr}}$ measured with the Prony brake, with the radius $R_{\mathrm{fr}}=75 \mathrm{~mm}$ of the friction wheel:

$M_{T}=F_{f r} \cdot R_{f r}$

The power output of the model $P_{\mathrm{M}}$ was determined by multiplying the torque $M_{\mathrm{T}}$ with the angular velocity $\omega=60 / \mathrm{n} \cdot 2 \cdot \pi \cdot R_{\mathrm{fr}}$ of the friction wheel

$P_{M}=\omega \cdot M_{T}$

The efficiency $\eta$ could then be calculated as the ratio of power $P_{\mathrm{M}}$ produced by the model, and the available wind energy $P_{\mathrm{w}}$ over the full frontal area $A$ of the model $\left(A=0.8 \times 0.6=0.48 \mathrm{~m}^{2}\right)$ for a density of air of $\rho_{\text {air }}=1.25 \mathrm{~kg} / \mathrm{m}^{3}$ and a measured wind speed $v_{\mathrm{w}}$ :

$P_{W}=A \cdot \rho_{\text {air }} / 2 \cdot v_{W}^{3}$

$\eta=\frac{P_{M}}{P_{W}}$

\section{Qualitative tests}

\subsection{Blade geometry}

Initially, the blades of the runner had a width of $370 \mathrm{~mm}$ and extended directly from the axis to the shroud, with a $5 \mathrm{~mm}$ gap between the blade and the outer wall. This geometry was deployed outside for first exploratory tests. It appeared however that the model was not self starting. For lower wind speeds below $3 \mathrm{~m} / \mathrm{s}$ the runner oscillated back- and forward, for higher wind speeds it moved slowly. An assessment of the situation led to the assumption that, with a static rotor, a hydrostatic pressure situation was generated at the inflow whereby the stagnation pressure of the air flow acted on one blade in the direction of rotation, but on the following blade against that direction. An analysis of pictures of Persian Wind Mills showed that there always was a gap of around $1 / 6$ of the blade width or more between blade and axis. This, it was realised, would create a very different flow condition where the air always flows through the box, see also [13]. The blade width was subsequently 
reduced to $300 \mathrm{~mm}$ with a $50 \mathrm{~mm}$ gap between blade and axis, and a $25 \mathrm{~mm}$ gap between blade and outer wall. The first tests were conducted with a torque of $0.02 \mathrm{Nm}$ due to bearing friction, i.e. without load applied to the Prony brake. The model self-started at around $1.5 \mathrm{~m} / \mathrm{s}$. The blade speed to wind speed ratio reached 1.5, and the maximum efficiency (bearing friction only) was determined as $15 \%$. The comparatively minor modification of the blade width had a dramatic effect on the performance.

\subsection{Wind tunnel tests}

A second preliminary test was conducted in the University of Southampton's Robert Mitchell wind tunnel facility. The working area of the wind tunnel has a cross section of $3.5 \times 2.4 \mathrm{~m}$. The model was placed on a $0.9 \mathrm{~m}$ high steel frame made up of $20 \times 40 \mathrm{~mm}$ hollow sections, Fig. 3a. Air flow velocities of $v_{\mathrm{w}}=2,3,4,5$ and $6 \mathrm{~m} / \mathrm{s}$ were employed. The maximum blockage ratio (ratio of model front area to cross sectional area of wind tunnel) was $5.7 \%$, so that noticeable blockage effects could be excluded. The maximum efficiency determined in the tests was $3.6 \%$, the highest blade to wind speed ratio was 0.3 . In addition, it was observed that for flow velocities of 5 and $6 \mathrm{~m} / \mathrm{s}$, strong horizontal oscillations of the experimental rig occurred after 20 to 30 seconds of air flow. From observations it was estimated that the oscillations had a magnitude of approximately 30 to $40 \mathrm{~mm}$, with a frequency of 2.5 to $3 \mathrm{~Hz}$. The dynamic excitation was unforeseen, so that no measurement equipment was available to record either magnitude or frequency. In the outside tests, such oscillations were never observed. Due to time restrictions (the wind tunnel was only available for 1.5 days), the reason for these oscillations could not be investigated further.

After intense discussion it was concluded that the horizontal oscillations were probably produced by periodic vortex shedding, since their frequency did not coincide with the frequency of blade passage of approximately $9 \mathrm{~Hz}$. Static tests indicated that a force of $200 \mathrm{~N}$ was required to cause a horizontal deflection of the frame of $20 \mathrm{~mm}$. The maximum aerodynamic force acting on the model was calculated as $14 \mathrm{~N}$ for a wind speed of $v_{w}=6 \mathrm{~m} / \mathrm{s}$. A periodic load must therefore have been present, whereby by chance the separation frequency coincided with the natural frequency of the modeland-frame system.

\section{Performance testing}

\subsection{Overview}

A series of performance tests with the model shown in Fig. 3a were carried out as part of an ongoing research programme at Southampton University [14], [15]. The aims of the tests were to determine the performance and to assess the effect of geometry modifications. The tests were conducted outside, in a $4 \mathrm{~m}$ wide, and approximately $50 \mathrm{~m}$ long road between a three and a four storey building on the University campus. Fig. $3 \mathrm{~b}$ shows the location, which constitutes something like an outdoor wind tunnel. 
a. Model (wind tunnel, from upstream) investigated, see table 1 :

Table 1: tests conditions for outside tests

\subsection{Data acquisition} minutes per test run.

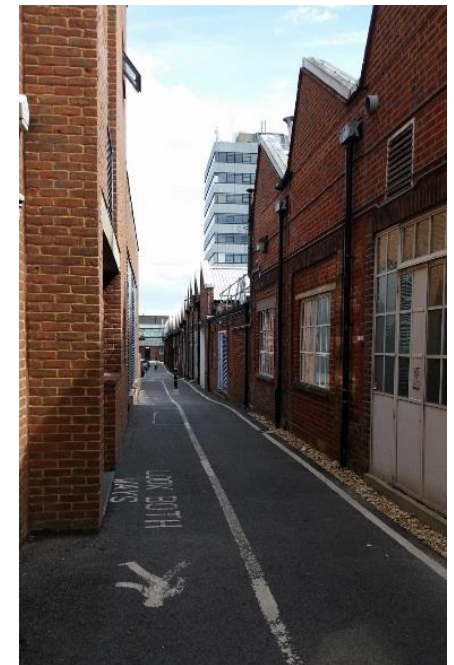

b. $T=$ Outside test location (view in wind direction)

Fig. 3: Model in wind tunnel and outside test location

Flow visualisation tests indicated a nearly unidirectional flow at the test site. Two geometries were

\begin{tabular}{|l|l|c|c|}
\hline $\mathrm{Nr}$ & Geometry & $\begin{array}{l}\text { Applied } \\
\text { force (N) }\end{array}$ & $\begin{array}{l}\text { Test } \\
\text { numbers }\end{array}$ \\
\hline 1 & Open downstream side & $0.2-2.2$ & $9-12$ \\
\hline 2 & $\begin{array}{l}\text { Right hand side of the downstream end of the } \\
\text { rotor covered by a curvature (shroud), see Fig. } 2\end{array}$ & $0.2-3.2$ & $13-18$ \\
\hline
\end{tabular}

In the tests, the wind speed, runner velocity and the friction force on the $200 \mathrm{~mm}$ diameter friction wheel was measured simultaneously. Measurements were taken at 0.1 second intervals for 3 to 5

a. Test 13 (only bearing friction)

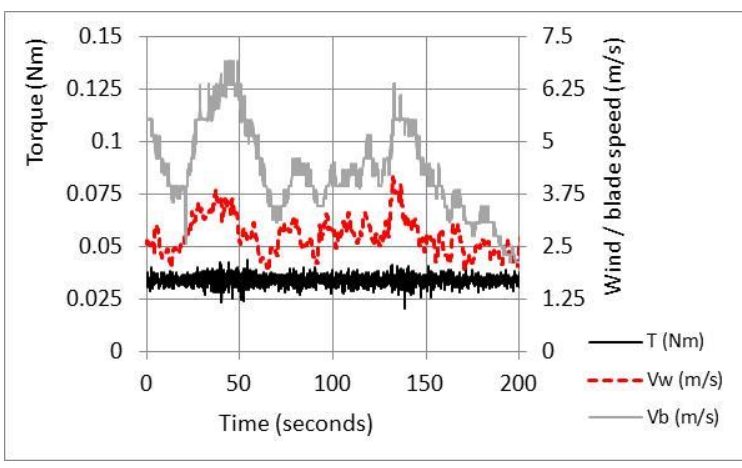

Fig. 4: Typical wind speed, runner speed and friction force record

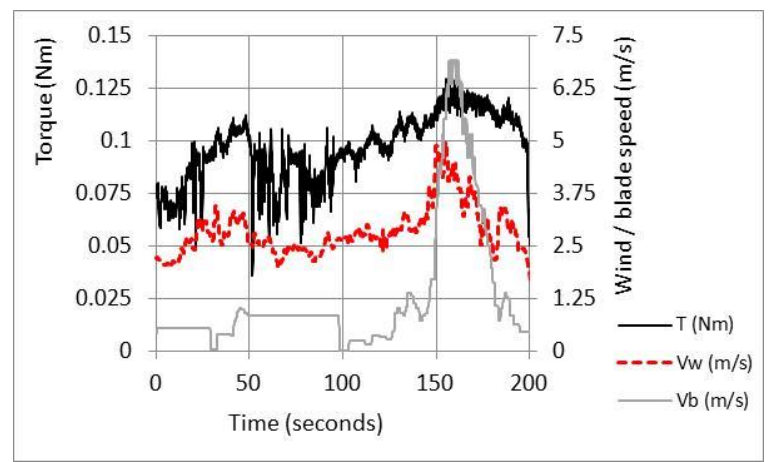

b. Test 16 (hanger $+1 \mathrm{~N}$ ) 
Fig. 4 shows two typical data records with wind speed, blade velocity and torque. In Fig. 4a, no load apart from the near constant bearing fiction is applied. The blade speed follows the wind speed closely and exceeds the wind speed by a factor of up to 2.2. Fig. $4 \mathrm{~b}$ shows the situation with load applied. The torque and the runner follow the wind speed approximately. The torque varies from $0.07 \mathrm{Nm}$ to $0.13 \mathrm{Nm}$, whilst the runner speed ranges from 0.56 to $7.0 \mathrm{~m} / \mathrm{s}$ with wind speed variation form 1.56 to $5 \mathrm{~m} / \mathrm{s}$. For higher wind speed, the runner speed exceeds the wind speed by a factor of nearly two.

\subsection{Power and efficiency}

In this section, the experimental results will be shown as original and non-dimensional data. The load had to be pre-set, and the wind speed could not be controlled. This means that every test run contains a multitude of conditions. In order to identify the main system characteristics, it was therefore decided to show not just power out against wind speed and efficiency against nondimensional blade speed, but also the relationships of actual and non-dimensional parameters. Fig. $5 a$ shows the power generated as a function of wind speed for both geometries.

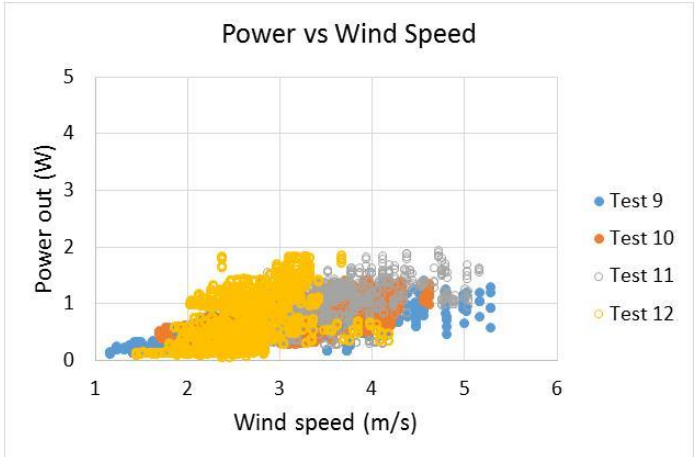

a. Geometry 1: downstream open

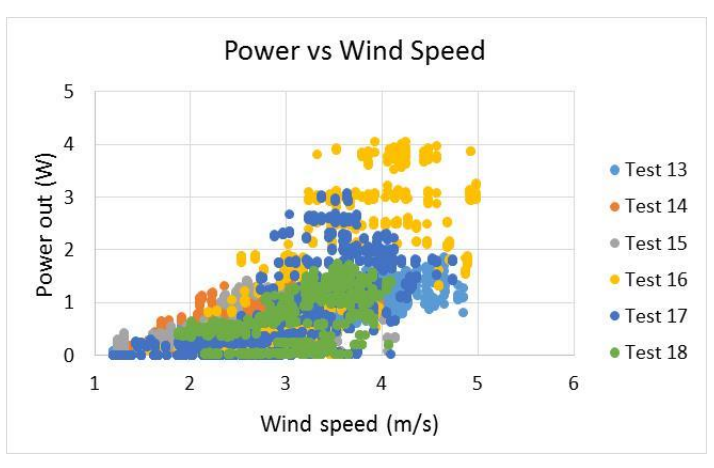

b. Geometry 2: downstream shroud

Fig. 5: Power and wind speed

For wind speeds of more than $3 \mathrm{~m} / \mathrm{s}$, the power generation for Geometry 2 is twice as high as that for Geometry 1. The efficiency graphs in Fig. 7 confirm the better power conversion for higher wind and runner velocities. The efficiencies for Geometry 2 reach 0.48 for a wind speed of $1.4 \mathrm{~m} / \mathrm{s}, 0.40$ for $2.5 \mathrm{~m} / \mathrm{s}$ and 0.2 for $5 \mathrm{~m} / \mathrm{s}$.

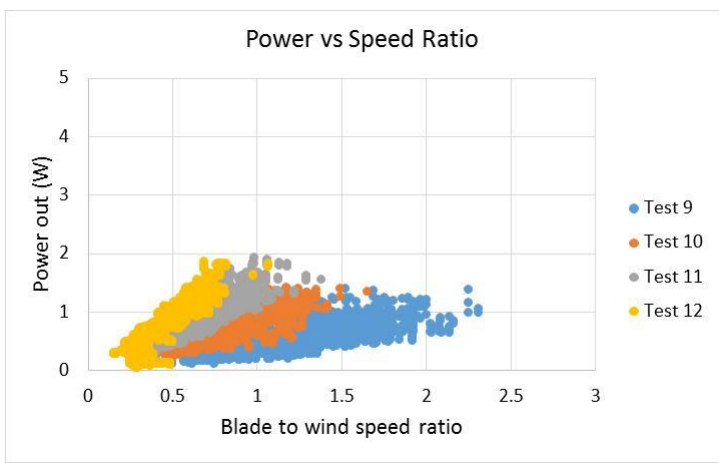

a. Geometry 1: downstream open

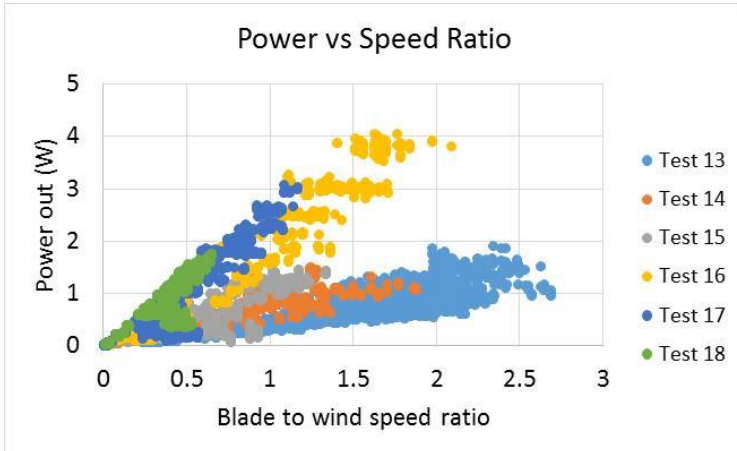

b. Geometry 2: with downstream shroud

Fig. 6: Power out as function of blade to wind speed ratio 
Fig 6 shows the power output as a function of the blade to wind speed ratio. Geometry 2 indicates a marked increase in power as well as a shift of the point of maximum power from wind speed ratios of $v_{B} / v_{w}=0.8$ to 1 (Fig. 6a, Geometry 1 ) to $v_{B} / v_{w}=1.0$ to 2 (Fig. 6b, Geometry 2).

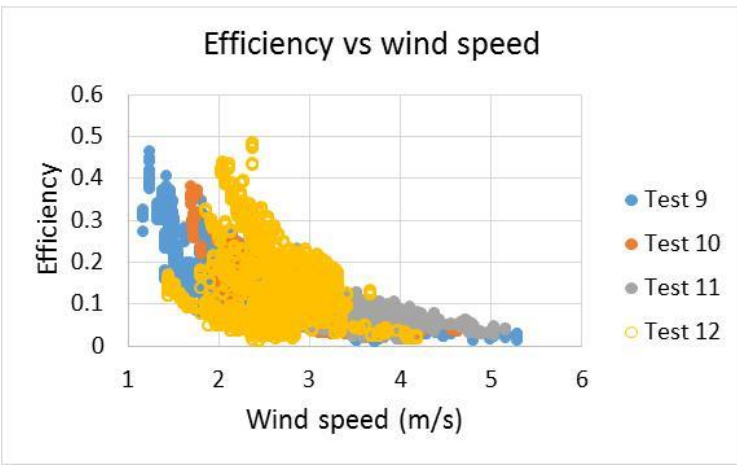

250

251

252

a. Geometry 1: downstream open

Fig. 7: Efficiency and wind speed positive effect for higher wind speeds.

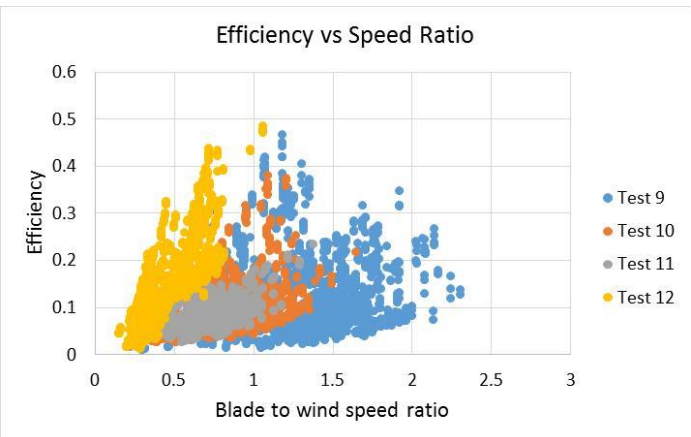

a. Geometry 1: downstream open
Fig. 8: Efficiency as function of blade to wind speed ratio increased power output.

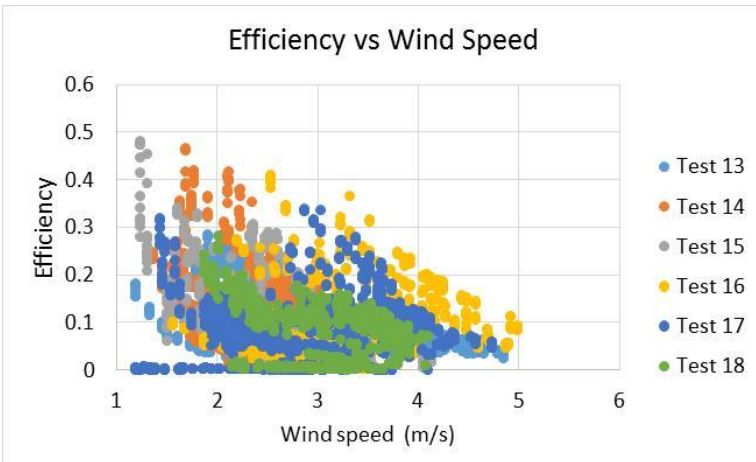

b. Geometry : with downstream shroud

In Fig. 7, efficiency is plotted against wind speed. The efficiencies were determined using the full frontal area of the model $\left(0.6 \times 0.8 \mathrm{~m}^{2}\right)$ as base. The efficiency for both geometries reach 0.45 to 0.5 for wind speeds between 1 and $2.5 \mathrm{~m}$, Fig. 7. For Geometry 1 , the efficiency then drops rapidly to reach 0.15 for $v_{w}=3.5 \mathrm{~m} / \mathrm{s}$ and 0.05 for $v_{w}=5 \mathrm{~m} / \mathrm{s}$, Fig. 7a. Geometry 2 here reaches an efficiency of 0.35 for $v_{w}=3.5 \mathrm{~m} / \mathrm{s}$, and 0.12 for $v_{w}=5 \mathrm{~m} / \mathrm{s}$, Fig. $7 \mathrm{~b}$. The shroud therefore has a substantial and

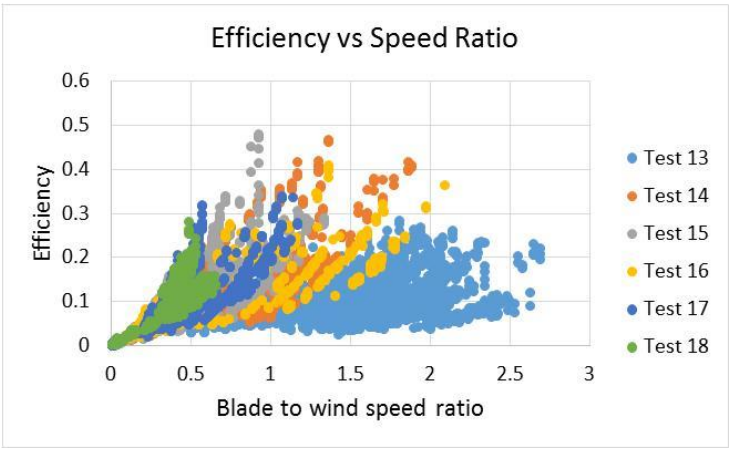

b. Geometry 2: with downstream shroud

The efficiency as function of the blade to wind speed ratio is finally shown in Fig. 8. Again, geometry 2 shows better results for higher blade to wind speed ratios $v_{B} / v_{w}$. Maximum efficiencies reach 0.42 to 0.5 for $v_{B} / v_{w}=0.75$ to 1.25 (Fig. 8a, Geometry 1 ), and 0.42 to 0.5 for $v_{B} / v_{w}=0.85$ to 1.8 (Fig. $8 b$, Geometry 2). Geometry 2 also allows for higher operational blade to wind speed ratios of up to 2.7. The downstream shroud therefore allows for higher runner speeds, better power conversion and 


\subsection{Qualitative tests}

270 The initial tests, which were conducted with only friction torque applied, resulted in a maximum blade to wind speed ratio of 1.5. The gap between blade and axis was found to be an essential detail of the system. The results from a three blade rotor without gap between blades and axis reported in the literature may also have been influenced by this effect [8], [9]. Numerical work [13] where a larger gap existed, indicated a maximum (free wheeling) blade to wind speed ratio of 5.4, substantially higher than the ratio of 0.44 given in [9]. This supports the argument for the necessity of the gap, although a speed ratio of 5.4 appears to be very high.

\subsection{Wind tunnel tests}

Tests were conducted in strong time constraints, only half an afternoon and one morning of wind tunnel time was available to the team. In the tests, the strong horizontal oscillations were noticed, but could not be followed up. The efficiencies in the wind tunnel tests were very low, as were the maximum blade to wind speed ratios with a ratio of 0.3 in the wind tunnel, and 1.5 in the initial outside experiments. This led to the conclusion that vortex shedding and dynamic response occurred in the wind tunnel. The highly variable wind speeds in the outside tests did not allow this effect to develop. So, the more regular and controlled conditions created a condition where unexpected fluid dynamic effects dominated the environment and consequently the measurements. If the results from the outdoor tests had not been available, and if the specific characteristics of the model had not created a visible dynamic response, then these effects would probably have gone unnoticed, and the interpretation of the results may have been misleading.

A short theoretical analysis showed that the Reynolds number for the tests was approximately $3 \times$ occurs at vertical cylinders, e.g. [16]. The shedding frequency $f$ can then be estimated as

$f=0.25 \cdot \frac{v}{D}$

With a velocity $v=6 \mathrm{~m} / \mathrm{s}$, and a principal dimension $D=0.6 \mathrm{~m} f$ becomes $2.5 \mathrm{~Hz}$, which is reasonably close to the observed oscillation. This effect needs to be investigated further to avoid (a) misinterpretation of wind tunnel results, and (b) structural problems at full scale.

\subsection{Outside tests}

It had been decided to conduct experiments in a narrow channel between two buildings since the costs for tests in a wind tunnel were too high. The disadvantages of outside tests are mainly the variable and unpredictable wind speed, and the uncertainty about wind direction. To some extent the latter factor could be balanced by choosing an appropriate site with temporary unidirectional flow conditions. The measurement system was designed accordingly so that wind speed, runner speed and friction force could be measured simultaneously. maximum blade to wind speed ratio of 2.5. This indicates the effect of the deflector, which funnels the air flow into the operating section. The efficiency is however not just a function of the applied torque blade speed ratio, but also of the actual wind speed, reaching a maximum for lower wind speeds and reducing to 0.4 for a wind speed of $5 \mathrm{~m} / \mathrm{s}$. This indicates that wind speed related 
Geometry 2 with a downstream shroud led to a significant improvement of the performance. With efficiencies of up to 0.5 , the values from the tests reported here are significantly larger than those reported in the literature (0.15). The experiments reported in the literature were however all conducted in wind tunnels, so that vortex shedding and the associated detrimental effects cannot be excluded. In addition, the effect of a downstream shroud to avoid counteracting forces on the rotor was not considered. In the numerical models it appears that the effect of downstream separation was not included either, which must lead to lower efficiencies.

\subsection{Comparison with reported results}

Table 2 shows the efficiencies and Tip Speed Ratios (TSR) from different resistance type VAWTs reported in the literature, the results from the current study and typical values for Darrieus-, H-Rotor and Horizontal Axis Wind Turbines (HAWT) for comparison. For this table, the TSR was used instead of the blade to wind velocity ratio employed previously in order to obtain data comparable with that given in the literature.

\begin{tabular}{|c|c|c|c|c|c|}
\hline $\mathrm{Nr}$ & Type & Efficiency & TSR & Comments & Ref. \\
\hline 1 & Persian Windmill & $\begin{array}{c}0.025- \\
0.07\end{array}$ & $\approx 0.5$ & Estimate from theory & [4] \\
\hline 2 & Darrieus turbine & 0.45 & 6 & Full scale tests & [2] \\
\hline 3 & $\mathrm{H}-$ Rotor turbine & 0.40 & 3.8 & Full scale tests & [2] \\
\hline 4 & HAWT & 0.48 & 6.8 & Full scale tests & [2] \\
\hline 5 & $\begin{array}{l}\text { Resistance type Sistan } \\
\text { type mill }\end{array}$ & 0.15 & 0.525 & No systematic tests & [5] \\
\hline 6 & Resistance type VAWT & 0.18 & 0.3 & $\begin{array}{l}\text { 3-blade rotor, static external } \\
\text { guide vanes, no gap between } \\
\text { blade and axis, wind tunnel tests }\end{array}$ & [9] \\
\hline 7 & Resistance type VAWT & 0.17 & $\begin{array}{c}0.40- \\
0.45\end{array}$ & $\begin{array}{l}8 \text { blades, blade width / radius = } \\
1 / 4, \text { large gap between blade and } \\
\text { axis, wind tunnel tests }\end{array}$ & [10] \\
\hline 8 & $\begin{array}{l}\text { Resistance type VAWT } \\
\text { Geometry } 1\end{array}$ & 0.036 & 0.3 & $\begin{array}{l}\text { Six blades, gap between axis and } \\
\text { blades, wind tunnel tests. Strong } \\
\text { flow-induced horizontal } \\
\text { oscillations observed }\end{array}$ & $\begin{array}{l}\text { This } \\
\text { study }\end{array}$ \\
\hline 9 & $\begin{array}{l}\text { Resistance type VAWT } \\
\text { Geometry } 1\end{array}$ & $\begin{array}{c}0.42- \\
0.5\end{array}$ & $\begin{array}{c}1.31- \\
2.19\end{array}$ & $\begin{array}{l}\text { Six blades, gap between axis and } \\
\text { blades, outside tests }\end{array}$ & $\begin{array}{l}\text { This } \\
\text { study }\end{array}$ \\
\hline 10 & $\begin{array}{l}\text { Resistance type VAWT } \\
\text { Geometry } 2\end{array}$ & $\begin{array}{c}0.42- \\
0.5\end{array}$ & $\begin{array}{l}1.51- \\
3.15\end{array}$ & $\begin{array}{l}\text { Six blades, gap between axis and } \\
\text { blades, downstream end half } \\
\text { closed, outside tests }\end{array}$ & $\begin{array}{l}\text { This } \\
\text { study }\end{array}$ \\
\hline
\end{tabular}

Table 2: Comparison of test results with results reported in the literature

The efficiencies for standard turbines range from 0.4 to 0.5 , similar to those reported in this study. Previous tests on resistance type VAWTs showed lower efficiencies of 0.15 to 0.18 , with tip speed ratios of 0.3 to 0.5 . The TSR values are significantly lower than those from the outside tests reported in this study of 1.31 to 3.15 (rows 9 and 10), but close to those from the wind tunnel tests (row 8). In the tests described in [9], the blade extends from the axis to the outer rim of the augmenting vane section. The gap between blade and axis, which the experiments described in this article showed to be very important, is missing. This may to some extent balanced by the fact that the model described in [9] only had three blades. 
335 Operational conditions in a natural environment may affect the performance of a wind turbine. Two aspects, the effect of cross winds or wind components normal to the prevailing wind direction and the effect of wind speeds exceeding the design wind speed will be discussed here briefly: Cross winds or wind vector components normal to the turbine axis can have negative effects on HAWTs, leading e.g. to additional dynamic loadings on the turbine blades. The VAWT described in this article is expected to tolerate large wind vector angles of up to 45 degrees to the rotor channel without additional effects, apart from a reduction in power output. The wind can enter the rotor channel from the deflector side for an angle of 45 degrees, from the rotor channel side at even larger angles. Here, the reduction in power would be more significant since a vector component of the air flow points against the direction of rotation. This may need to be addressed by a slight change in geometry. The turbulence associated with cross winds should not have any significant effect on power generation since the VAWT relies on resistance drag conversion rather than aerodynamic effects.

The rotor speed is limited by the design speed of the generator. An further increase of the wind speed above design speed could theoretically be compensated by the rotor speed remaining constant, so that the blade speed ratio and the efficiency reduces. However, say for a $20 \%$ wind speed increase the available power would increase by $73 \%$ whilst the efficiency only drops by $4 \%$. Reducing the rotor speed further to match the power rating at a lower speed would overload the generator. A solution for this problem could be to turn the shroud, the external hull, slightly out of the wind direction. This will reduce the wind energy input, so that the effective power generated by the rotor and its speed can therefore remain constant. Contrary to HAWT's, stall does not occur for resistance type wind turbines. It can be expected that the turbine will remain operational for wind speeds significantly higher than the design wind speed. The effect of an increased wind speed and an oblique wind angle on flow induced vibrations will need to be assessed in wind tunnel experiments. If the flow induced vibrations are linked to the flow through the rotor, then it may be necessary to shut down operation by turning the outer shroud into the wind direction. In general, the authors expect that the resistance-type VAWT has a wider operational range of wind speeds than airfoil-type VAWTs and HAWTs.

\subsection{Application}

With mechanical efficiencies of 0.5 , the resistance VAWT is in interesting alternative to propeller type turbines. A $6 \mathrm{~m}$ diameter, $10 \mathrm{~m}$ high rotor could produce approximately $30 \mathrm{~kW}$ electrical energy for the wind speed of $12.5 \mathrm{~m} / \mathrm{s}$. Since the resistance type machines do not rely on aerodynamic uplift, stall - i.e. the sudden loss of uplift under high air flow velocities / high angles of incidence - cannot occur. Operation in higher wind speeds may be possible by turning the rotor channel slightly out of the wind as described in the previous section. Also, it can be expected that the effect of turbulence will be small, making the application in built-up areas easier. All these aspects require further investigation.

The original Sistan wind mills were built for wind coming from just one direction. The modern VAWTs are envisaged to have a movable outer shroud, which can turn the opening into the prevailing wind direction. Contrary to current propeller type HAWTs, the runner will not have to be moved, reducing structural complexity. 


\section{Conclusions}

A series of quantitative and qualitative model tests with a vertical axis, resistance wind turbine were conducted in order to determine geometric parameters and to assess the performance. Qualitative tests served to identify important design details. Wind tunnel tests led to the discovery of unexpected aerodynamic effects. Outside tests showed the actual performance under variable conditions. The following conclusions were drawn:

- A gap between blades and axis of approximately $1 / 6$ of the blade width is essential for the functionality of the resistance type VAWT.

- In wind tunnel test, periodic vortex shedding occurred, which created very high forces on the turbine model and strongly reduced the performance

- Two geometries - Geometry 1 with an open downstream side, and Geometry 2 with a closed downstream side - were investigated.

- With minimum torque applied, blade velocities can reach up to 2.5 times the wind speed.

- Geometry 2 with showed the better performance. Efficiencies ranged from 0.42 to 0.5 and 0.25 for blade to wind speed ratios of $v_{B} / v_{W}=0.85$ to 1.8 and 2.5.

It appears that the Sistan type VAWT could be an interesting wind energy converter for effective building integration and possibly even for application in tower-like structures.

\section{References}

[1] Mertens, S. (2002). Wind energy in urban areas: Concentrator effects for wind turbines close to buildings. Refocus, 3(2), 22-24.

[2] Eriksson, S., Bernhoff, H., \& Leijon, M. (2008). Evaluation of different turbine concepts for wind power. Renewable and Sustainable Energy Reviews, 12(5), 1419-1434.

[3] Al-Hassan AY, Hill DR. Islamic technology: an illustrated history. Cambridge: Cambridge University Press; 1986.

[4] Shepherd, D. G. (1990). Historical development of the windmill (Vol. 4337). National Aeronautics and Space Administration, Office of Management, Scientific and Technical Information Division.

[5] Müller, G., Jentsch, M. F., \& Stoddart, E. (2009). Vertical axis resistance type wind turbines for use in buildings. Renewable Energy, 34(5), 1407-1412.

[6] Kaboldy - Own work, CC BY-SA 3.0, https://commons. wikimedia. org/w/index.php?curid=8537002Bayoumi,

[7] Bellebaum, J., Korner-Nievergelt, F., Dürr, T., \& Mammen, U. (2013). Wind turbine fatalities approach a level of concern in a raptor population. Journal for Nature Conservation, 21(6), 394-400.

[8] Chong, W. T., Poh, S. C., Abdullah, N., Naghavi, M. S., \& Pan, K. C. 2010. Vertical Axis Wind Turbine with Power-Augmentation-Guide-Vane for Urban High Rise Application. World Renewable Energy Congress XI. 25-30 September 2010, Abu Dhabi, UAE.

[9] Chong, W. T., Fazlizan, A., Poh, S. C., Pan, K. C., Hew, W. P., \& Hsiao, F. B. (2013). The design, simulation and testing of an urban vertical axis wind turbine with the omni-directionguide-vane. Applied Energy, 112, 601-609. 
[10] Rolland, S. A., Thatcher, M., Newton, W., Williams, A. J., Croft, T. N., Gethin, D. T., \& Cross, M. (2013). Benchmark experiments for simulations of a vertical axis wind turbine. Applied energy, 111, 1183-1194.

[11] Burlando, M., Repetto, M. P., Freda, A., \& Ricci, A. (2014) Wind tunnel and CFD models of a vertical axis wind turbine with power augmentation guide vanes. The 6th International Symposium on Computational Wind Engineering - CWE2014, Hamburg / Germany.

[12] Burlando, M., Ricci, A., Freda, A., \& Repetto, M. P. (2015). Numerical and experimental methods to investigate the behaviour of vertical-axis wind turbines with stators. Journal of Wind Engineering and Industrial Aerodynamics, 144, 125-133.

[13] Baïri, A., Crua, C., Bauzin, J. G., \& Baïri, I. (2016). Aerodynamical phenomena in a large top covered wind mill with vertical axis wind turbine. International Journal of Numerical Methods for Heat \& Fluid Flow, 26(1), 365-378. Kerri M. 2016. The Persian Wind Mill for building integrated wind energy generation. Individual Project Report. University of Southampton.

[15] Chavuchoglu M. 2016. The Persian Wind Mill for building integrated wind energy generation. Individual Project Report. University of Southampton.

435 [16] Liu, H. (1990). Wind engineering: a handbook for structural engineering. Pearson Education. 